\title{
高䶔心筋梗塞患者の下肢筋カと筋カトレーニング
}

\author{
山㟝裕司

\section{LEG STRENGTH AND WEIGHT TRAINING IN ELDERLY PATIENTS WITH MYOCARDIAL INFARCTION}

\author{
HIROSHI YAMASAKI, PT. MA.
}

\begin{abstract}
The present two studies were aimed at investigating the necessity of weight training in elderly patients with myocardial infarction.

Study 1 investigated the muscle strength and incidence of gait disorders in 300 patients with myocardial infarction. The age-and gender-related differences in knee extension peak torque were significant $(\mathrm{p}<0.01)$. Peak torque in the $70 \sim 79$ and $80 \sim 89$ yr-old women was extremely low $(0.88,0.75 \mathrm{~N} \cdot \mathrm{m} / \mathrm{kg})$. Gait disorders occurred frequently in older patients amounting to approximately $30 \%$ of women $>70$ years of age.

Study 2 was conducted to clarify the effects of combined aerobic and weight training. 35 elderly patients with myocardial infarction were assigned to two groups : Group I performed combined aerobic and weight training $(n=18)$ and group II did not perform physical training $(n=17)$. Physical training was prescribed for 8 weeks. Weight training of knee extensors was performed at $60 \%$ of one repetition maximum and aerobic training was prescribed at the anaerobic threshold (AT) level heart rate. After 8 weeks, the improvement in peak torque and gait speed was significantly greater in group I $(32 \%, 12 \%)$ than group II $(9 \%, 3 \%)$. The improvement in peak $\mathrm{VO}_{2}$, exercise time, AT was significantly greater in group I than group II. Increased peak torque was associated with increased gait speed and exercise time (modified protocol) $(r=0.71, r=0.53)$. On the other hand, increased peak torque was not associated with increased peak $\mathrm{VO}_{2}$ and AT. Combined aerobic and weight training is an effective method for increasing muscle strength, gait speed and exercise capacity.

In conclusion, physical training in the recovery phase of elderly patients with myocardial infarction should include weight training.
\end{abstract}

(Jpn. J. Phys. Fitness Sports Med. 1999, $48: 559 \sim 568$ )

key words : myocardial infarction, elderly patients leg strength, weight training, exercise capacity

I. 粕

心疾患患者の運動療法では心機能や有酸素作業 能力の低下が主容な問題とされてきた。しかし， 最近になって重症心疾患患者において下肢筋力低 下や骨格筋萎縮が顕著なことが報告されるように なり ${ }^{1,2)}$ ，心疾患患者の骨格筋筋力が注目されて いる. さらに，本邦の高齢心疾患患者では入院前 から身体活動量の低下している場合が多く, 入院 中の安静臥床を契機として歩行困難となり, 通 常の運動療法が適応できないケースが少なくな い3)。したがって，特に高齢心疾患患者では運動
能力の制限要因として下肢筋力に注目すべきと考 えられる。

一方，心疾患患者に対する筋力トレーニングに ついては，その有効性と安全性について数多くの 報告がなされているが4 6)，筋力水準の低い高 齢心疾患患者を対象とした研究はない.したがっ て, 筋力トレーニングが高齢心筋梗塞患者の運動 能力に及ほす影響については検討の余地が残され ている.

以上の点から, 今回 2 つ研究を実施した. 第 一は高齢心筋梗塞患者の下肢筋力の実態を把握す るために心筋梗塞患者の膝伸展筋力および歩行障

聖マリアンナ医科大学病院リハビリテーション部 Dept. of Rehabilitation Medicine, St. Marianna University School of 
害の出現状況について調査した．第二には高龄心 筋梗塞患者に対して下肢筋カトレーニングを併用 した運動療法を実施し，筋力トレーニングが歩行 能力や運動耐容能に及ほす影響について検討し た.

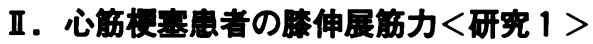

\section{A. 対象}

対象は平成 5 年 4 月から平成 9 年 4 月までの期 間に聖マリアンナ医科大学病院ハートリハビリ テーションセンターにおいて入院期プログラムを 施行し，かつ㮏伸展筋力の測定を実施できた50歳 以上の心筋梗塞患者 300 例で, 年龄は $66.3 \pm 8.3$ 歳, 男性206例，女性94例である。 なお，脳血管 障害や荷重関節の整形外科疾患を有する症例は対 象から除外した。 心筋梗塞発症前に明らかな歩行 障害を呈した症例はなかった。

\section{B. 方法}

膝伸展筋力の測定は心筋梗塞発症後一か月以上 経過し, 症候限界性運動負荷試験によって低強度 の運動負荷における心筋虚血や運動誘発性不整脈 がないことを確認した後に行った。測定には Cybex 社製 Cybex II ${ }^{+}$を用い, 60度/秒の角速 度で全力で 5 回の㮏関節屈曲伸展運動をさせた。 測定值はトルク曲線から直接最大䐂伸展ピークト ルク值を読み取り，体重の影箘を考虑して腅伸展 ピークトルクを体重で除した值(以下, 滕伸展ピー クトルク体重比）を求めた。 なお, 本研究では右 脚の結果をデータとして採用した。筋力測定中に は心電図モニターを監視し，測定前後に聴診法に よって血圧測定を行った。

歩行障害の出現状況については, 入院期リハビ リテーションプログラムの廊下歩行に際して, 手 すりや歩行器, 杖などの歩行補助具を必要とした 症例を歩行障害の出現例とした。

統計的手法としては 2 元配置分散分析と $\chi^{2}$ 検定を用い, 㮏伸展ピークトルク体重比と歩行障 害の出現状況を比較した。

\section{C. 結果}

Table 1 は膝伸展ピークトルク体重比の平均值 を性別，年代別に示したものである．男性，女性 とも高龄者において㮏伸展ピークトルク体重比は 有意に低值を示した $(\mathrm{p}<0.01)$ ．また，いずれの 年代においても男性に比べ女性で膝伸展ピークト ルク体重比は低值であった $(\mathrm{p}<0.01)$.

Table 1. Knee extension peak torque/Body weight

\begin{tabular}{ccc}
\hline $\begin{array}{c}\text { Age Range, } \\
\text { Year }\end{array}$ & $\mathrm{N} \cdot \mathrm{m} / \mathrm{kg}$ & $\begin{array}{c}\text { Women } \\
\mathrm{N} \cdot \mathrm{m} / \mathrm{kg}\end{array}$ \\
\hline $50 \sim 59$ & $1.77 \pm 0.30(\mathrm{n}=68)$ & $1.25 \pm 0.22(\mathrm{n}=19)$ \\
$60 \sim 69$ & $1.53 \pm 0.34(\mathrm{n}=87)$ & $1.04 \pm 0.27(\mathrm{n}=36)$ \\
$70 \sim 78$ & $1.42 \pm 0.28(\mathrm{n}=38)$ & $0.88 \pm 0.28(\mathrm{n}=29)$ \\
$80 \sim$ & $0.98 \pm 0.28(\mathrm{n}=13)$ & $0.75 \pm 0.21(\mathrm{n}=10)$ \\
Age $^{*}: \mathrm{p}<0.01$, Gender & $\# \mathrm{p}<0.01$ \\
\hline
\end{tabular}

Values are means $\pm \mathrm{SD}$.

* Age effect in the absence of age-gender interaction.

\# Gender effect in the absence of age-gender interaction.

Table 2 は同様に歩行障害の出現率について見 たものである．高齢者において出現率は有意に高 かった $(\mathrm{p}<0.01)$ 。また，60，70歳代では男性に 比べ女性において出現率は有意に高く,70歳以上 の高龄女性では，その約 $30 \%$ に歩行障害の出現 を認めた。

Table 2. The incidence of gait disorders in patients with acute myocardial infarction

\begin{tabular}{|c|c|c|c|c|}
\hline $\begin{array}{l}\text { Age Range, } \\
\text { year }\end{array}$ & $\begin{array}{l}\text { Men } \\
+/-\end{array}$ & $\begin{array}{c}\text { Women } \\
+/-\end{array}$ & $\chi^{2}$ & p-value \\
\hline $50 \sim 59$ & $0 / 68(0 \%)$ & $1 / 18(5 \%)$ & 3.62 & $<0.1$ \\
\hline $60 \sim 69$ & $2 / 85(2 \%)$ & $8 / 28(22 \%)$ & 13.53 & $<0.01$ \\
\hline $70 \sim 79$ & $3 / 35(8 \%)$ & $9 / 20(31 \%)$ & 5.99 & $<0.05$ \\
\hline $80 \sim$ & $3 / 10(23 \%)$ & $3 / 7(30 \%)$ & 0.14 & NS \\
\hline
\end{tabular}

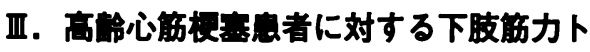 レーニングが员的能力に及ぼす影要 <研究 $2>$}

A. 対象

対象は65歳以上の高齢心筋梗塞患者35例で, 年 
齢は72.9土5.8歳, 男性19例, 女性16例である. これらの対象を以下の 2 群に分類した.すなわち, 下肢の筋カトレーニングを含む監視型運動療法を 施行したI 群(18例) と, 同時期に他院より心肺運 動負荷試験目的で当センターを受診し, 運動療法 は特別に指導されなかったII群(17例)である．な お運動負荷試験を虚血性心電図変化, 不整脈, 収 縮期血圧低下で終了した症例は対象から除外し た. 両群の臨床的背景について Table 3 に示す. 初回検查時点における年齢, 性別, 身長, 体重, peakCK-MB 值, 心筋梗塞部位, 冠動脈病変枝数, 最高酸素摂取量 (以下, peak $\mathrm{VO}_{2}$ ), 最大歩行ス ピード, 膝伸展ピークトルクには群間で有意な差 を認めなかった。 なお, この研究中, 投与薬物に 変更はなかった。

\section{B. 方法}

発症から 1 か月の時点と 3 か月の時点で滕伸展 筋力と歩行スピードの測定, および心肺運動負荷
試験を実施した.

\section{1. 膝伸展筋力の測定}

㮏伸展筋力の測定には Cybex 社製 Cybex II ${ }^{+}$ 用い, 研究一と同様の方法で膝伸展ピークトルク を求めた。 また，筋カトレーニングを実施した症 例では OG 技研社製 N-K テーブルを使用し， 膝伸展筋の 1 Repetition Maximum (以下, 1 RM) を測定した。 $1 \mathrm{RM}$ は N一K テーブル上に椅子坐 位をとり膝関節 90 度屈曲から膝を完全伸展させ得 る最大の重量を測定した. 測定に際しては疲労を 考慮し， 5 施行のうちに最大重量が測定できるよ うに配慮した。なお，いずれも右脚の結果をデー タとして採用した。

\section{2. 歩行スピードの測定}

測定は助走路を設け，計測開始地点のテープを 越えた接床から $10 \mathrm{~m}$ 先のテープを越えた接床ま での時間を計測した．歩行は極力早く歩くよう指 導し， 2 回の計測のうち時間の短い記録を採用し た. そして，最大歩行速度を算出した。

Table 3. Subject characteristics

\begin{tabular}{|c|c|c|}
\hline & $\begin{array}{l}\text { Group I } \\
\mathrm{n}=18\end{array}$ & $\begin{array}{c}\text { Group II } \\
\mathrm{n}=17\end{array}$ \\
\hline Age (yrs) & $72.7 \pm 6.2$ & $73.1 \pm 5.4$ \\
\hline Gender (male/female) & $10 / 8$ & $9 / 8$ \\
\hline Height $(\mathrm{cm})$ & $160 \pm 6$ & $158 \pm 7$ \\
\hline Weight $(\mathbf{k g})$ & $55.5 \pm 9.9$ & $52.3 \pm 7.6$ \\
\hline Peak CK-MB (mIU/ml) & $257 \pm 215$ & $264 \pm 150$ \\
\hline Anterior MI & 7 & 6 \\
\hline Inferior MI & 7 & 7 \\
\hline Extensive Anterior MI & 3 & 3 \\
\hline others & 1 & 1 \\
\hline \multicolumn{3}{|l|}{$\begin{array}{l}\text { Number of patients with } \\
\text { significant diameterstenosis }\end{array}$} \\
\hline$(\geqq 75 \%)$ of coronary artery & \multicolumn{2}{|c|}{ (after PTCA) } \\
\hline 0,1 & 12 & 13 \\
\hline 2 & 4 & 3 \\
\hline 3 & 2 & 1 \\
\hline \multicolumn{3}{|l|}{ Treadmill protocol } \\
\hline Standard/Modified & $8 / 10$ & $9 / 8$ \\
\hline Peak $\mathrm{VO}_{2}(\mathrm{ml} / \mathrm{min} / \mathrm{kg})$ & $17.6 \pm 4.3$ & $17.9 \pm 2.8$ \\
\hline Maximum gait speed $(\mathrm{m} / \mathrm{sec})$ & $1.46 \pm 0.26$ & $1.45 \pm 0.29$ \\
\hline Knee extension peak torque $(\mathrm{N} \cdot \mathrm{m})$ & $62.4 \pm 19.4$ & $65.1 \pm 24.3$ \\
\hline
\end{tabular}

Values are means $\pm S D$. 
3. 心肺運動負荷試験

運動負荷試験にはフクダ電子社製トレッドミル MAT一2500，運動負荷システム ML 5000 および ミナト医科学社製 RM 300, Medical Gas Analy. zer MG 360 を使用し，12誘導心電図，心拍数, 血圧ならびに呼気ガスデータを連続測定した．運 動負荷プロトコールは TABLE 4 に示す著者らの 開発した 2 種類のランプ負荷プロトコールを用い だ).なお, 歩行速度の遅い修正プロトコール(以 下，修正プロトコール）は標準プロトコールのス ピードについていけない症例に対して用いた。運 動負荷試験は症候限界性とし，中止基準は日本循 環器学会の基準を参考にした ${ }^{8)}$.そして, peak $\mathrm{VO}_{2}$, 運動時間, Anaerobic Threshold (以下, AT), 最高酸素脈(以下, peakO $\mathrm{O}_{2}$ pulse), 最高心 拍数 (以下, peakHR), 最高収縮期血圧 (以下, peakSBP)，最高ガス交換比(以下，peakGER）を 求めた.

4. 運動療法

運動療法期間は退院後 8 週間, 週 3 回の頻度で 監視型にて施行した，有酸素トレーニングにはト レッドミル，または自転車エルゴメータを用い， 目標心拍数の強度で30分間施行した。目標心拍数 は心肺運動負荷試験より得られた ATレベルの 心拍数の 90 ～100\%に設定した。 また，有酸素卜 レーニング前後には 2 種類のストレッチング(下 腿三頭筋，大腿四頭筋）を施行した，筋力トレー ニングは上記した有酸素トレーニング前に，㮏伸 展筋ならびに下腿三頭筋に対して実施した。膝伸 展筋の負荷強度は $1 \mathrm{RM}$ の $60 \%$ とした，反復回数 は 5 回を 1 セットとし，4〜6セット実施した.

筋収縮時間は約 5 秒とし，休止時間は 5 秒以上設 けるように指導した， $1 \mathrm{RM}$ は 1 ～调間ごとに 測定し，負荷強度の再設定を行った。下腿三頭筋 のトレーニングは片脚立位での calf raise 5 回 1 セットとし，4－6セット実施した。.いずれの 運動療法中も，心電図モニターを常時監視し，聴 診法によって血圧測定を行った。 なお，この筋力 トレーニングの安全性については我々の先行研究 によって確認されている6).

検査や運動療法の実施に際しては，その内容と
目的を患者に説明し，同意のもとに施行した。

\section{5. 解析方法}

I，II 群間で筋力，歩行スピード，運動負荷試 験結果の変化について比較検討した．統計的手法 としては，分散分析および Bonferroni の方法を 使用した。 また，膝伸展筋力の変化が運動能力に 与える影響について，ピアソンの相関係数を用い て検討した。いずれの検定においても有意水準は 危険率 $5 \%$ とした。

\section{C. 結果}

今回の筋力測定中ならびに筋力トレーニング中 には，モニター心電図上 $1 \mathrm{~mm}$ 以上の ST 下降や， 新たな不整脈の出現，ならびに不整脈の増悪は認 めなかった。

\section{1. 膝伸展筋力 (Table 5)}

膝伸展ピークトルクは初回検査時点に比較し, 最終検查時点で両群とも有意に増加した（I 群： $\mathrm{p}<0.01$, II 群 : $\mathrm{p}<0.01)$. 㮏伸展ピークトルク の変化率は I 群 $32 \%$, II 群 $9 \%$ で，II 群に比較し， I 群で有意に高い値を示した $(\mathrm{p}<0.01)$ ．Ｉ群に おける $1 \mathrm{RM}$ 值も同様に $52 \%$ の有意な增加を示し た $(\mathrm{p}<0.01)$.

2. 歩行スピード(Table 5)

歩行スピードは I 群で有意に増加したが $(\mathrm{p}<$ 0.01)，II 群では有意な変化を認めなかった．変 化率についてもI 群で有意に大きい值を示した $(\mathrm{p}<0.01)$. I， II 群の全症例を対象として見た 場合, 㮏伸展ピークトルクの変化率と歩行スピー ドの変化率のあいだには $\mathrm{r}=0.71$ の有意な正相 関を認めた $(\mathrm{p}<0.01)$.

\section{3．心肺運動負荷試験結果 (Table 6)}

初回検査時点においては, いずれの指標も群間 で有意差を認めなかった.

peak $\mathrm{VO}_{2}$ はI 群において $18 \%$ の増加を示した が $(\mathrm{p}<0.01)$, II 群では有意な変化を認めなかっ た. peak $\mathrm{VO}_{2}$ の変化率もII群に比較し I 群で有 意に大きかった $(\mathrm{p}<0.01)$.

運動時間は標準プロトコール，修正プロトコー ルともに，I群で有意な増加を示した $(\mathrm{p}<0.01)$. II 群では修正プロトコールにおいて $5 \%$ の増加を 
Table 4. Treadmill protocol

\begin{tabular}{rccccc}
\hline & \multicolumn{2}{c}{ Standard protocol } & \multicolumn{2}{c}{ Modified protocol } \\
\hline Stagh & $\begin{array}{c}\text { Duration } \\
(\mathrm{min})\end{array}$ & $\begin{array}{c}\text { Speed } \\
(\mathrm{mile} / \mathrm{hr})\end{array}$ & $\begin{array}{c}\text { Grade } \\
(\%)\end{array}$ & $\begin{array}{c}\text { Speed } \\
(\mathrm{mile} / \mathrm{hr})\end{array}$ & $\begin{array}{c}\text { Grade } \\
(\%)\end{array}$ \\
\hline 1 & 3 & 1.0 & 0.0 & 1.0 & 0.0 \\
2 & 1 & 2.0 & 0.0 & 1.5 & 0.0 \\
3 & 1 & 2.0 & 3.5 & 1.5 & 3.5 \\
4 & 1 & 2.0 & 7.0 & 1.5 & 7.0 \\
5 & 1 & 2.0 & 10.5 & 1.5 & 10.5 \\
6 & 1 & 2.0 & 14.0 & 1.5 & 14.0 \\
7 & 1 & 2.5 & 14.0 & 1.5 & 17.5 \\
8 & 1 & 2.5 & 16.0 & 1.5 & 21.0 \\
9 & 1 & 2.5 & 19.0 & 1.5 & 24.0 \\
10 & 1 & 2.5 & 22.0 & 1.7 & 24.0 \\
11 & 1 & 2.7 & 22.0 & 1.8 & 25.5 \\
12 & 1 & 3.0 & 22.0 & 2.0 & 25.5 \\
13 & 1 & 3.2 & 22.0 & 2.2 & 25.5 \\
14 & 1 & 3.4 & 22.0 & & \\
15 & 1 & 3.4 & 24.0 & & \\
16 & 1 & 3.4 & 25.0 & & \\
\hline
\end{tabular}

Table 5. Changes in knee extensor strength and gait speed

\begin{tabular}{ccccc}
\hline & & Initial & Final & $\%$ Change \\
\hline Knee extension & Group I & $62.4 \pm 19.4$ & $82.1 \pm 18.8^{\#}$ & $32 \%$ \\
Peak torque $(\mathrm{N} \cdot \mathrm{m})$ & Group II & $65.1 \pm 24.3$ & $70.8 \pm 25.4^{\#}$ & $9 \%$ \\
1 Repetition muximum $(\mathrm{kg})$ & Group I & $5.8 \pm 2.6$ & $8.8 \pm 2.9^{\#}$ & $52 \%$ \\
Maximum gait speed $(\mathrm{m} / \mathrm{sec})$ & Group I & $1.46 \pm 0.26$ & $1.64 \pm 0.28^{\#}$ & $12 \%$ \\
& Group II & $1.45 \pm 0.29$ & $1.49 \pm 0.31$ & $3 \%$
\end{tabular}

Values are means $\pm S D$. Significant change from the initial to final value within the group ; ${ }^{\#} p<0.01$. Significant difference between the groups $;{ }^{*} \mathrm{p}<0.01$.

認めたが有意ではなかった．増加率はいずれのプ ロトコールにおいてもI 群で有意に大きかった $(\mathrm{p}<0.01)$.

AT, peak $\mathrm{O}_{2}$ pulse も, I 群においてのみ有意 な增加を認め $(\mathrm{p}<0.01)$, 增加率についても I 群 で有意に大きかった $(\mathrm{p}<0.01, \mathrm{p}<0.05)$.

peakHR， peakGER はI 群で有意に増加したが $(\mathrm{p}<0.05), \quad$ II 群では変化を認めなかった. peakSBP は両群ともに有意な変化を認めなかっ た.

4. 滕伸展ピークトルクと運動能力諸指標の 変化率の関連

Table 7 に標準プロトコールにおいて運動負荷
試験を行った症例の滕伸展ピークトルクの変化率 と運動能力諸指標の変化率の関連を示した．腺伸 展ピークトルクの変化率と有意な正相関を示した 指標は歩行スピードの変化率のみであった $(\mathrm{r}=$ $0.51 ; \mathrm{p}<0.05)$. peak $\mathrm{VO}_{2}$, 運動時間, AT の変 化率の間には，それぞれ有意な関連を認めた。

Table 8 には修正プロトコールにおいて運動負 荷試験を行った症例の㮏伸展ピークトルクの変化 率と運動能力諸指標の変化率の関連を示した，滕 伸展ピークトルクの変化率と有意な正相関を示し た指標は歩行スピードと運動時間の変化率であっ た $(\mathrm{r}=0.74 ; \mathrm{p}<0.01, \mathrm{r}=0.53 ; \mathrm{p}<0.05)$.また, 歩行スピードの変化率と運動時間の変化率の間に 
Table 6. Changes in exercise capacity

\begin{tabular}{|c|c|c|c|c|}
\hline & & Initial & Final & $\%$ Change \\
\hline \multirow[t]{2}{*}{ Peak $\mathrm{VO}_{2}(\mathrm{ml} / \mathrm{min} / \mathbf{k g})$} & Group I & $17.6 \pm 4.3$ & $20.9 \pm 4.5^{\# 1}$ & $18 \%$ \\
\hline & Group II & $17.9 \pm 2.8$ & $18.5 \pm 2.6$ & $3 \%-$ \\
\hline \multicolumn{5}{|l|}{ Exercise time (min) } \\
\hline \multirow[t]{2}{*}{ Standard protocol } & Group I & $8.0 \pm 1.6$ & $9.4 \pm 1.8^{\# 1}$ & $18 \%$ \\
\hline & Group II & $8.1 \pm 1.4$ & $8.2 \pm 1.6$ & $1 \%$ \\
\hline \multirow[t]{2}{*}{ Modified protocol } & Group I & $7.2 \pm 1.2$ & $9.2 \pm 2.2^{\# 1}$ & $28 \% 7$ \\
\hline & Group II & $8.0 \pm 1.2$ & $8.4 \pm 1.3$ & $5 \%$ \\
\hline \multirow[t]{2}{*}{ Anaerobic thresold $(\mathrm{ml} / \mathrm{min} / \mathbf{k g})$} & Group I & $13.0 \pm 2.3$ & $14.4 \pm 2.5^{\# 1}$ & $11 \% 7$ \\
\hline & Group II & $13.5 \pm 1.8$ & $13.3 \pm 1.7$ & $-1 \%-$ \\
\hline \multirow[t]{2}{*}{ Peak $\mathrm{O}_{2}$ pulse (ml/beat) } & Group I & $8.4 \pm 2.4$ & $9.4 \pm 2.8^{\# 1}$ & $12 \%$ \\
\hline & Group II & $8.6 \pm 2.8$ & $8.7 \pm 2.4$ & $1 \%$ \\
\hline \multirow[t]{2}{*}{ Peak heart rate (bpm) } & Group I & $129 \pm 18$ & $136 \pm 19^{\# 1}$ & $5 \%$ \\
\hline & Group II & $130 \pm 15$ & $129 \pm 15$ & $-1 \%$ \\
\hline \multirow[t]{2}{*}{ Peak blood pressure $(\mathrm{mmHg})$} & Group I & $185 \pm 19$ & $188 \pm 22$ & $2 \%$ \\
\hline & Group II & $187 \pm 26$ & $195 \pm 35$ & $2 \%$ \\
\hline \multirow[t]{2}{*}{ Peak gas exchange ratio } & Group I & $1.08 \pm 0.10$ & $1.14 \pm 0.09^{\# 1}$ & $6 \%$ \\
\hline & Group II & $1.09 \pm 0.10$ & $1.08 \pm 0.08$ & $-1 \%$ \\
\hline
\end{tabular}

Values are means $\pm S D$. Significant change from the initial to final value within the group; ${ }^{1} p<0.01$, $\# 2$ p $<0.05$.

Significant difference between the groups $;{ }^{* 1} p<0.01,{ }^{* 2} ; p<0.05$.

Table 7. Correlations among percentage change of physical performance parameters (standard protocol)

\begin{tabular}{lcccc}
\hline & Gait speed & Exercise time & Peak $\mathrm{VO}_{2}$ & AT \\
\hline Peak torque & $0.51^{* 2}$ & 0.29 & 0.03 & -0.11 \\
Gait speed & & 0.32 & -0.02 & 0.14 \\
Exercise time & & & $0.72^{* 1}$ & $0.64^{* 1}$ \\
Peak $\mathrm{VO}_{2}$ & & & & $0.61^{* 1}$ \\
\hline
\end{tabular}

Exercise capacity is measured by standard protocol.

$* 1 \mathrm{p}<0.01, * 2 \mathrm{p}<0.05$

Table 8. Correlations among percentage change of physical performance parameters (modified protocol)

\begin{tabular}{lcccc} 
& Gait speed & Exercise time & Peak $\mathrm{VO}_{2}$ & AT \\
\hline Peak torque & $0.74^{* 2}$ & $0.53^{* 2}$ & 0.16 & 0.25 \\
Gait speed & & $0.59^{* 1}$ & 0.20 & 0.17 \\
Exercise time & & & $0.49 * 2$ & 0.37 \\
Peak $\mathrm{VO}_{2}$ & & & & $0.49 * 2$ \\
\hline
\end{tabular}

Exercise capacity is measured by modified protocol.

$* 1 \mathrm{p}<0.01, * 2 \mathrm{p}<0.05$

も $\mathrm{r}=0.59$ の有意な相䦛を認めた. その他, peakVO $\mathrm{V}_{2}$ と運動時間, AT の変化率の間に有意 
入院期の歩行障害の出現状況について調査した. 男性心筋梗塞患者の膝伸展ピークトルク体重比は 80 歳以上の症例において $0.98 \mathrm{~N} \cdot \mathrm{m} / \mathrm{kg}$ と極端に 低值を示し, 歩行障害の出現率も23\% と高率で あった. 60〜70歳代における歩行障害の出現率は 低值であったが，膝伸展ピークトルク体重比は， 蛭田たち 9 が報告した健常高齢者の值をそれぞれ $20 \%$ 前後下回っており, 下肢筋力低下の存在が確 認された. 女性での筋力低下はさらに顕著で， 60 歳代の $22 \%, 70$ 歳以上の症例の30\%には歩行障害 を入院中に認めていた，入院中の歩行障害の原因 については明らかではないが，入院後新たに出現 したものであり, 安静臥床にもとずく廃用性筋力 低下がこの誘因になったものと推察された．入院 期プログラムは短縮しているものの, 室内歩行が 自由になるには発症から 7〜10日の日数が必要で ある、また，筆者の先行研究では ${ }^{3)}$, 歩行障害例 の多くは心不全などの急性期合併症を生じてお り, 平均臥床期間は16日であった。廃用性筋力低 下については一日当たり 1 〜 $1.5 \%$ の低下が報告 されており ${ }^{10)}$ ，患者には10１5\% 程度の筋力低 下は生じていたものと考えられた。

筋力水準からみた場合, 運動器疾患のない高齢 入院患者を对象とした研究では ${ }^{11)}, 1.2 \mathrm{~N} \cdot \mathrm{m} / \mathrm{kg}$ を下回る筋力において, 膝伸展ピークトルク体重 比の低下にともなって明らかに最大歩行スピード は低下した．また， $0.58 \mathrm{~N} \cdot \mathrm{m} / \mathrm{kg}$ を下回る高齢者 では院内独歩自立例を全く認めなかった。 Judge et al. は ${ }^{12)}, 0.86 \mathrm{~N} \cdot \mathrm{m} / \mathrm{kg}$ を境として comfortable gait における歩行速度が低下することを報告して いる. 今回の70, 80 歳代の高龄女性の膝伸展ピー クトルク体重比はそれぞれ $0.88,0.75 \mathrm{~N} \cdot \mathrm{m} / \mathrm{kg}$ であり，筋力水準の低い症例では筋力低下が歩行 能力を制限していた可能性が高いものと推察され た。

以上のことから，高齢心筋梗塞患者の下肢筋力 水準は低く, 特に女性では下肢筋力低下が歩行能 力の制限要因になり得るものと考えられた.

次いで，第二研究として高龄心筋梗塞患者に対 して筋カトレーニングを併用した回復期運動療法 を施行し,その効果について検討した. 滕伸展ピー
クトルクの増加率は I 群32\%, II 群 $9 \%$ であり, 運動療法を施行したI 群で明らかに良好であっ た. 心疾患患者に対する筋カトレーニングの効果 については, 40〜60\% 1 RM の強度, 8〜12週間 のトレーニング期間によって 20 - 30\% ${ }^{13 \sim 15)}$ と報 告されている．I 群における $1 \mathrm{RM}$ 值は $52 \%$ 增加 しており，増加率はこれらの報告に比較して良好 であった．筋力增強はトレッドミルや自転車エル ゴメータによる有酸素トレーニングによっても可 能である. しかし，心疾患患者を対象とした先行 研究では有酸素トレーニングによる㮏伸展筋 1 RM 值の増加率は 5 〜 9 にすぎず15 17), 今回 の筋力増強には筋力トレーニングの影響が大きい ものと推察された. 以上のことから高齡心筋梗塞 患者の筋力を効果的に増強するには筋力トレーニ ングの併用が必須と考えられた。

歩行スピードは運動療法を施行したI 群で12\% の改善を認めたが，II 群では有意な変化を認めな かった. また, 滕伸展ピークトルクと歩行スピー ドの変化率の間には全体で $\mathrm{r}=0.71$ の正相関を 認めた. したがって, 筋力の増加は少なからず歩 行スピードの改善に影響したものと推察された。

健常高齢者を対象とした先行研究でも，下肢筋力 トレーニングによる最大歩行スピードの改善が報 告されており ${ }^{18 〜 20)}$ ，今回の結果はこれを支持す るものと考えられた。

運動耐容能に対する効果をみた場合, 運動㞠法 を処方したI群で peak $\mathrm{VO}_{2}$ ，運動時間，AT, peakO $\mathrm{O}_{2}$ pulse の改善は良好であり，心疾患患者 を対象としたこれまでの研究と同様の結果であっ $た^{21 \sim 24)}$. peakHR の増加の背景については不明 であるが，同時に peakGER が增加していたこと から，より高い歩行努力を行ったことがその原因 と推察された ${ }^{25)}$. 一方, II 群では運動耐容能に 有意な変化を認めず, 高齡心筋梗塞患者の運動耐 容能を改善させる上では, 回復期運動療法の実施 が必要不可欠なものと考えられた。

次に下肢筋力や歩行スピードの変化が運動耐容 能に及ほす影響について検討した。㮏伸展ピーク トルク, 歩行スピードの変化率と修正プロトコー ルによって測定された運動時間の変化率の間に有 
意な相関を認めた $(r=0.53, r=0.59)$. 筋力ト レーニングと最大作業能力の関連を見た先行研究 では，健常高齢者において筋力トレーニングがト レッドミル歩行時間や自転車駆動時間を増加させ ることが明らかとなっている ${ }^{26 〜 28)}$ 。また, 心疾 患患者では筋力トレーニングを併用した運動療法 が, 有酸素トレーニング単独のものよりも最大作 羓能力を向上させる上で有効なことが報告されて いる14,15). したがって，本研究結果もこれらの 先行研究を一部支持するものと考えられた. しか し, 今回標準プロトコールで測定された運動時間 は滕伸展ピークトルクの変化率と有意な関連を示 さず $(\mathrm{r}=0.29)$, 一方で peakVO $2, \mathrm{AT}$ の変化率 との間に高い相関を認めた $(r=0.72, r=0.64)$.

この背景としては, 標準プロトコールを使用した 症例の滕伸展筋力 $(1.32 \mathrm{~N} \cdot \mathrm{m} / \mathrm{kg})$ や歩行スピード $(1.60 \mathrm{~m} / \mathrm{sec})$ が初回検查時点において, 修正プロ トコールを使用した症例よりも $(0.94 \mathrm{~N} \cdot \mathrm{m} / \mathrm{kg}$, $1.29 \mathrm{~m} / \mathrm{sec})$ 明らかに高かったことが考えられた。 つまり，標準プロトコールを使用した症例では， 初回検查時点で筋力や歩行スピードが標準プロト コールを遂行する上で十分であり，運動時間の変 化は有酸素作業能力の変化によって強く規定され たものと推察された，逆に，修正プロトコールを 使用した症例では運動時間と AT の変化率の間 に有意な関連を認めず，また peak $\mathrm{VO}_{2}$ との相関 係数も比較的低值に止まった。したがって，筋力 や歩行スピードが低い症例では, 有酸素作業能力 の改善以外にも, 筋力增強が最大作業能力を改善 させる上で重要なものと考えられた。この他，今 回の筋力トレーニングは, 先行研究 $26-28)$ よりも トレーニング期間や運動種目が少なく，このこと も標準プロトコールで測定された運動時間と筋力 の変化率の間に有意な関連を認めなかった一因と 推察された。

次に，筋力と有酸素作業能力の関連について検 討した. 滕伸展ピークトルクの変化率と有酸素作 業能力の指標となる peak VOO, AT の変化率の 間には，いずれのプロトコールにおいても有意な 関連を認めなかった. Jondeau et al. は ${ }^{29)}$ 心不全 患者を対象とした研究で，運動に参加した筋量と peak $\mathrm{VO}_{2}$ の間に有意な関連を認めている. 一方, Frontera et al. ${ }^{30)}$ は筋力トレーニングよって健 常高齢者の筋断面積は $28 \%$ 增加したが, peak $\mathrm{VO}_{2}$ の增加は $6 \%$ に止まったことを報告し ている．その他の健常成人を対象とした研究では 筋力トレーニングが peak $\mathrm{VO}_{2}$ に与える影響につ いては否定的な意見が多い28,31). したがって, 筋カトレーニングが高龄心筋梗塞患者の peak $\mathrm{VO}_{2}$ に与える影響については，あったとし ても極めて小さいものと推察された.

以上のことから, 高齢心筋梗塞患者における筋 カトレーニングは, 運動能力の中でも, 歩行スピー ドや最大作業能力の改善に寄与するものと推察さ れた。

\section{V. 括}

本研究では高龄心筋梗塞患者の運動療法におけ る筋力トレーニングの必要性について検討した.

1. 回復期心筋梗塞患者の滕伸展筋力および歩 行障害の出現状況について調查した結果, 高齡心 筋梗塞患者の下肢筋力低下は著しく，特に高龄女 性の㮏伸展筋力は歩行能力を低下させうる水準に あった。

2. 高齢心筋梗塞患者に対する下肢筋力トレー ニングを併用した運動療法は，運動療法を実施し ない場合に比較し, 筋力増強, 歩行スピードの改 善, 運動耐容能の改善を図る上で有効であった。

3. 下肢筋力増強は, 特に歩行スピード, 最大 作業能力の改善に寄与していた。

以上のことから高齢心筋梗塞患者の運動療法に は筋カトレーニングを併用すべきである.

（受理日 平成11年 6 月30日）

\section{文}

1) Sunnerhagen, K. S., Cider, A. S. A., Schaufelberger, M., Hedberg, M. and Grimby, G. Muscular perform ance in heart failure. J. Cardiac. Failure., (1998), 4. 97-104.

2) Buller, N. P., Jones, D. and Poole-Wilson, P. A. Direct measurement of skeletal muscle fatigue in patients with chronic heart failure. Br. Heart. J., (1991), 65, 20-24.

3）山崎裕司, 山田純生, 渡辺解, 大森豊, 深井 
和良, 三好邦達, 田辺一彦, 長田尚彦, 急性心筋 梗塞にみられる歩行障害, 理学療法学, (1993), 20, 307-311.

4) McCartney, N. Role of resistance training in heart disease. Med. Sci. Sports. Exerc., (1998), 30, 396402.

5) Verrill, D., Shoup, E., McElveen, G., Witt, K., Bergey, D. Resistive exercise training in cardiac patients. Sports. Med., (1992), 13, 171-193.

6) 山崎裕司, 山田純生, 渡辺 敏, 長谷川輝美, 青 木治人, 田辺一彦, 長田尚彦, 伊東春樹, 村山正博, 回復期心筋梗塞患者に対する筋力トレーニングの 安全性, PT ジャーナル，(1996)，30，120-124.

7) 山田純生, 山崎裕司, 前田秀博, 村山正博. Anaerobic Threshold 測定用 Treadmill Protocol に ついて, 体力科学, (1989), 38, 656

8）日本循環器学会 “運動に関する診療基準委員会” 1989年度報告 “運動療法に関する診療基準”, Jap. Circ. J., (1991)，55(Suppl III)，386-397.

9）蛭田秀一, 島岡みどり, 小林寛道, 高齢者の等速 性最大筋力, 体力科学, (1988), 37, 481 .

10) Muller, E. A. Influence of training and inactivity on muscle strength. Arch. Phys. Med. Rehabil., (1970), 51, 449-462.

11）山崎裕司, 横山仁志, 青木詩子, 黒澤保壽, 山田 純生, 青木治人, 田辺一彦, 長田尚彦, 高齡患者 の膝伸展筋力と歩行速度、独歩自立との関連, 絵 合リハ, (1998), 26, 689-692.

12) Judge, J. O., Underwood, M. and Gennosa, T. Exercise to improve gait velocity in older persons. Arch. Phys. Med. Rehabil., (1993), 74, 400-406.

13) Haennel, R. G., Koon-Kang, T., Quinney, H. A. and Kappagoda, C. T. Effects of Hydraulic circuit training following coronary artery bypass surgery. Med. Sci. Sports.Exer., (1991), 23, 158-165.

14) Keremen, M. H., Stewart, F. K. J., Gillilan, R. E., Ewart, C. K., Valenti, S. A., Manley, J. D. and Keremen, M. D. Circuit weight training in cardiac patients. J. Am. Coll. Cardiol., (1986), 7, 38-42.

15) McCartney, N., McKelvie, R. S., Haslam, D. R. and Jonse, N. L. Usefulness of weightlifting training in improving strength and maximal power output in coronary arterydisease. Am. J. Cardiol., (1991), 67, 939-945.

16) Beniamini, Y., Rubenstein, J. J., Faigenbaum, A. D., Lichtenstein, A. H. and Crim, M. C. High-intensity strength training of patients enrolled in an outpatient cardiac rehabilitation program. J Cardiopulmonary. Rehabil., (1999), 19, 8-17.

17）山崎裕司, 山田純生, 田辺一彦, 長田尚彦, 村山 正博, 心疾患患者に対する筋力トレーニング, 理 学療法学, (1995), 22, 427-432

18) Hunter, G. R., Treuth, M. S., Weinsier, R. L., Kekes-Szabo, T., Kell, S. H., Roth, D. L. and Nicbolson, $C$. The effects of strength conditioning on older women's ability to perform daily tasks. J. Am.
Geriatr. Soc., (1995), 43, 756-760.

19) Connelly, D. M. and Vandervoort, A. A. Improvement in knee extensor strength of institutionalized elderly women after exercise with ankle weights. Physiother. Can., (1995), 47, 15-23.

20) Lord, S. R., Lloyd, D. G., Nirui, M., Raymond, J., Williams, P. and Stewart, R. A. The effect of exercise on gait patterns in older women. J. Gerontol., (1996), 51, 64-70.

21) Foelicher, V., Jensen, D.; Genter, F., Sullivan, M., McKirnan, M. D., Witztum, K., Scharf, J., Strong, M. L. and Ashburn, W. A randomized trial of exercise training in patients with coronary heart disease. J. A. M. A., (1984), 252, 1291-1297.

22) Paterson, D. H., Shephard, R. J., Cunningham, D., Jones, N. L. and Andrew, G. Effect of physical training on cardiovascular function following myocardial infarction. J. Appl. Physiol., (1979), 47, 482-489.

23) Blumenthal, J. A., Rejeski, W. J. Walsh-Riddle, M., Emery, C. F., Miller, H., Roark, S., Ribisl, P. M., Morris, P. B., Brubaker, P. and Williams, R. S. Comparison of high- and low-intensity exercise training early after acute myocardial infarction. Am. J. Cardiol., (1988), 61, 26-30.

24）岩崎達弥，慢性期心筋梗塞患者における Anaerobic Threshold の経時的変化とその規定因子について. 日本臨床生理学会雑誌, (1988), 21, 117-133.

25) Savin, W. M., Haskell, W. L., Houston, N. and DeBusk, R. F. Improvement in aerobic capacity soon after myocardial infarction. J. Cardiac. Rehab., (1981), 1, 337-342.

26) Parker, N. D., Hunter, G. R., Treuth, M. S, KekesSzabo, T., Kell, S. H., Weinsier, R. L. and White, $M$. Effect of strength training on cardiovascular responses during a submaximul walk and a weightloaded walking test in older females. J. Cardiopulmonary. Rehabil., (1996), 16, 56-62.

27) Ades, P. A., Ballor, D. L., Ashikaga, T., Utton, J. L. and Nair, K. S. Weight training improves walking endurance in healthy elderly persons. Ann. Int. Med., (1996), 124, 568-572.

28) McCartney, N., Hicks, A. L., Martin, J. and Webber, C. E. A longitudinal trial of weight training in the eldery. J. Gerontol., (1996), 51, 425-433.

29) Jondeau, G., Katz, S. D., Zohman, L., Goldberger, M., McCarthy, M., Bourdarias, J. P and LeJemtel, T. H. Active skeletal muscle mass and cardiopulmonary reserve. Circulation., (1992), 86, 1351-1356.

30) Frontera, W. R., Meredith, C. N. and Evans, W. J. Strength training and determinants of $\mathrm{VO}_{2}$ max in older men. J. Appl. Physiol., (1990), 68, 329-333.

31) Hickson, R. C., Rosenkoetter, M. A. and Brown, M. $M$. Strength training effects on aerobic power and short-term endurance. Med. Sci. Sports. Exer., (1980), 12, 336-339. 